\title{
Whole Body Bone Scan for Detecting Missed Bone Injuries in Multiple Trauma Patients
}

\author{
Hong Yoon Jeong, M.D., Im-kyung Kim, M.D., Seo Hee Choi, M.D., \\ Changro Lee, M.D., Man Ki Ju, M.D., Ph.D. \\ Department of Surgery, Yonsei University College of Medicine, Seoul, Korea
}

\author{
Correspondence to: \\ Man Ki Ju, M.D., Ph.D. \\ Department of Surgery, \\ Gangnam Severance Hospital, \\ Yonsei University College of \\ Medicine, 211 Eonju-ro, \\ Gangnam-gu, Seoul 06273, \\ Korea \\ Tel: +82-2-2019-3893 \\ Fax: +82-2-3462-5994 \\ E-mail: mkju@yuhs.ac
}

Purpose: Patients with multiple traumas often experience multiple fractures that are missed or overlooked, despite the use of imaging, careful history taking, and physical examinations. This study aimed to evaluate the usefulness of whole body bone scan (WBBS) for detecting missed bone injuries in patients with multiple traumas.

Methods: We evaluated 30 patients with multiple traumas who underwent WBBS at single tertiary referral center between March 2008 and February 2016. We assessed the association of patient demographics with WBBS uptake as a binomial outcome variable.

Results: There were no significant differences in patient demographics by WBBS. The mean injury severity score did not differ by WBBS (18.1 in the WBBS-negative group vs. 18.4 in the WBBS-positive group), and duration from admission to the evaluation of the WBBS was similar (5.4 days in both groups). The most common uptake site in the WBBS was the ribs $(n=7)$, followed by the tibia $(n=3)$, skull $(n=2)$, ankle $(n=1)$, and sternum $(n=1)$. None of the missed injuries required further treatment, such as manual reduction or surgery.

Conclusion: WBBS was useful for detecting missed bone injuries in patients with multiple trauma. (J Acute Care Surg 2017;7:56-60)

Key Words: Whole body bone scan, Missed injuries, Multiple trauma

Received January 19, 2017, Revised August 16, 2017, Accepted August 19, 2017

Copyright $(2017$ by Korean Society of Acute Care Surgery

(c) This is an Open Access article distributed under the terms of the Creative Commons Attribution Non-Commercial License (http://creativecommons.org/licenses/by-nc/4.0) which permits unrestricted non-commercial use, distribution, and reproduction in any medium, provided the original work is properly cited.

ISSN 2288-5862(Print), ISSN 2288-9582(Online)

https://doi.org/10.17479/jacs.2017.7.2.56

\section{Introduction}

Trauma surgeons inevitably treat patients with multiple major traumas, and delays in the diagnosis or treatment of these patients are inexcusable. Therefore, the Advanced Trauma Life Support Course states that the standard of care for these patients should involve a rapid primary survey of life-threatening injuries followed by a head-to-toe secondary survey [1].

However, patients with multiple traumas often experience multiple injuries that are missed or overlooked despite imaging, careful history taking, and physical examinations. Furthermore, during the early phase of multiple traumas, the patient's extreme pain and decreased orientation can make it difficult to detect all of their injuries. Previous studies have reported that standard radiography failed to identify injuries in $0.6 \sim 65 \%$ of trauma patients [2,3], and in up to $50 \%$ of rib fracture cases [4]. Thus, there is growing interest in diagnostic tools that can complement the current imaging modalities. The present study aimed to evaluate the usefulness of whole body bone scan (WBBS) for detecting missed bone injuries in patients with multiple traumas. 


\section{Methods}

This study was a retrospective single-center study conducted at a tertiary referral hospital in South Korea from March 2008 to February 2016. This study was approved by the Institutional Review Board of Gangam Severance Hospital, Yonsei University, Seoul, Korea.

\section{Study population}

During the study period, a total of 78 patients with multiple traumas had moderate to severe injuries evaluated by injury severity scores (ISS). The initial diagnoses were made using plain radiography, ultrasonography, computed tomography (CT), or magnetic resonance imaging to examine the region(s) of interest based on patients' symptoms and physical examinations. All patients were initially treated in the emergency room until their vital signs had stabilized.

\section{Whole body bone scan}

The WBBS was performed using Tc-99m methylene diphosphonate $(20 \mathrm{mCi})$ at $5 \sim 7$ days after the admission. Among 78 patients, the WBBS was performed only in 30 patients. Other 48 patients could not undergo WBBS due to critical injuries with unstable hemodynamics. The scanning was performed using a single-lens camera with a high-resolution collimator. Two experienced nuclear medicine physicians reviewed the anteroposterior, oblique, and localized views of the region(s) of interest. The patients were divided into two groups (WBBS-negative vs. WBBS-positive group) based on the presence or absence of uptakes in the WBBS. Areas suspected of bone injuries in the WBBS were finally diagnosed after the performance of additional examinations such as further X-rays or CT scans.

\section{Statistical analysis}

All statistical analyses were performed using IBM SPSS Statistics ver. 19.0 (IBM Co., Armonk, NY, USA). Categorical variables were analyzed using the chi-square test or Fisher's exact test. Continuous variables were analyzed using Student's t-test. p-values of $<0.05$ were considered statistically significant.

\section{Results}

The 30 patients included 12 patients with uptakes in the WBBS (WBBS-positive group) and 18 patients without uptakes in the WBBS (WBBS-negative group). The patients' baseline characteristics are shown in Table 1 . We did not identify any statistically significant differences between the two groups, which exhibited similar values for their mean ISS and duration from the admission to the evaluation of the WBBS. The most common mechanism of injury in both groups was the traffic accident. When compared the sites of detected fractures at the initial diagnosis, there was no statistical difference between the two groups. Chest including

Table 1. Comparisons of patient characteristics between the two groups

\begin{tabular}{|c|c|c|c|}
\hline Variable & $\begin{array}{l}\text { WBBS-negative } \\
\quad(\mathrm{n}=18)\end{array}$ & $\begin{array}{l}\text { WBBSpositive } \\
\qquad(\mathrm{n}=12)\end{array}$ & pvalue \\
\hline Gender & & & 1.000 \\
\hline Male & 11 (61.1) & $8(66.7)$ & \\
\hline Female & $7(38.9)$ & $4(33.3)$ & \\
\hline Age (y) & $50.6 \pm 17.0$ & $43.2 \pm 13.0$ & 0.190 \\
\hline Injury severity score & $18.1 \pm 7.8$ & $18.4 \pm 6.8$ & 0.897 \\
\hline Mechanisms of injury & & & 0.372 \\
\hline Fall & $4(22.2)$ & $1(8.3)$ & \\
\hline Passenger TA & $3(16.7)$ & $6(50.0)$ & \\
\hline Pedestrian TA & $5(27.8)$ & $2(16.7)$ & \\
\hline Motorcycle TA & $3(16.7)$ & $1(8.3)$ & \\
\hline Others $^{\mathrm{a})}$ & $3(16.7)$ & $2(16.7)$ & \\
\hline Reasons for admission & & & 0.881 \\
\hline Multiple fractures & $5(27.8)$ & $2(16.7)$ & \\
\hline Hemoperitoneum & $10(55.6)$ & $8(66.7)$ & \\
\hline Panperitonitis & $2(11.1)$ & $1(8.3)$ & \\
\hline Others & $1(5.6)$ & $1(8.3)$ & \\
\hline Sites of detected fractures & & & 0.258 \\
\hline Face & $2 / 26(7.7)$ & $3(25.0)$ & \\
\hline Upper extremities & $1 / 26(3.8)$ & $2(16.7)$ & \\
\hline Chest & $12 / 26(46.2)$ & $5(41.7)$ & \\
\hline Pelvis and sacrum & 4/26 (15.4) & $2(16.7)$ & \\
\hline Thoraciclumbar spine & $3 / 26(11.5)$ & $0(0)$ & \\
\hline Lower extremities & 4/26 (15.4) & $0(0)$ & \\
\hline Hospital stay (d) & $10.8 \pm 6.9$ & $10.2 \pm 5.6$ & 0.802 \\
\hline $\begin{array}{l}\text { Duration from admission to } \\
\text { evaluation of the WBBS (d) }\end{array}$ & $5.4 \pm 2.9$ & $5.4 \pm 3.0$ & 0.980 \\
\hline
\end{tabular}

Values are presented as number (\%) or mean \pm standard deviation. WBBS: whole body bone scan, TA: traffic accident.

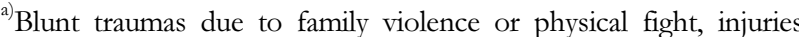
from sports. ${ }^{\text {b) }}$ Contains duplication, and "chest" includes ribs and clavicles. 
ribs and clavicle was the most common site of fractures in both groups, and other fractures on face, pelvis, spine and upper and lower extremities were detected at the initial diagnosis (Table 1).

\section{Presence of missed injuries in the whole body bone scan}

One example of missed rib fractures is shown in Fig. 1. Plain radiography did not identify any bony lesions, although the WBBS

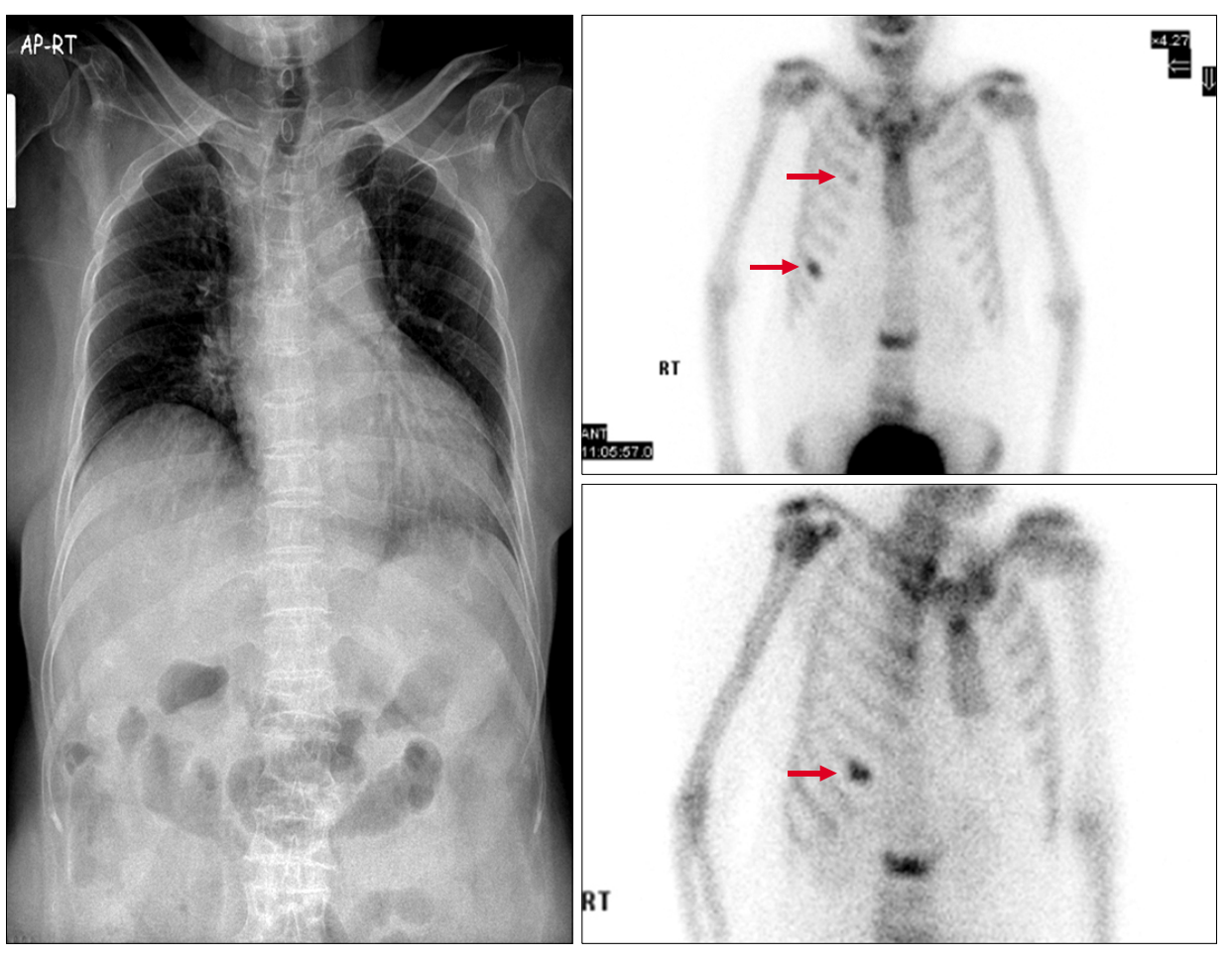

Fig. 1. Normal chest radiography (left) and whole-body bone scanning (right, RT) revealing increased uptake in the right anterior 3rd and 7th ribs (arrows).

Table 2. Additional imaging studies for a definitive diagnosis in the WBBS-positive group

\begin{tabular}{|c|c|c|c|c|}
\hline $\begin{array}{c}\text { Patient } \\
\text { (gender/age, y) }\end{array}$ & Mechanism & $\begin{array}{c}\text { Areas suspected injuries } \\
\text { in the WBBS }\end{array}$ & $\begin{array}{l}\text { Initial } \mathrm{P} / \mathrm{Ex} \text { or } \\
\text { simple } \mathrm{X} \text {-rays }\end{array}$ & $\begin{array}{l}\text { Additional studies } \\
\text { for confirmation }\end{array}$ \\
\hline $\mathrm{F} / 49$ & Blunt trauma & Lt. frontotemporal skull & $\begin{array}{l}\text { Orbital wall fracture on } \\
\text { X-ray (skull series) }\end{array}$ & Brain CT \\
\hline $\mathrm{M} / 46$ & Fall & Rt. 6th $\sim 7$ th anterior ribs & Normal & Chest CT \\
\hline $\mathrm{M} / 31$ & Blunt trauma & Rt. 7th anterolateral ribs & Normal & Chest CT \\
\hline $\mathrm{F} / 63$ & Pedestrian TA & Rt. proximal tibia & $\begin{array}{l}\text { Normal on } \mathrm{P} / \mathrm{Ex} \\
\text { (X-rays were not taken) }\end{array}$ & $\begin{array}{l}\text { X-ray: knee both-oblique, knee } \\
\text { standing AP (both) view }\end{array}$ \\
\hline $\mathrm{F} / 57$ & Passenger TA & Lt. 7 th $\sim 9$ th anterior ribs & Normal & Chest CT \\
\hline $\mathrm{F} / 35$ & Passenger TA & Rt. 7 th $\sim 8$ th costochondral junction & Normal & Chest CT \\
\hline $\mathrm{M} / 29$ & Passenger TA & Lt. distal tibia & $\begin{array}{l}\text { Normal on } \mathrm{P} / \mathrm{Ex} \\
\text { (X-rays were not taken) }\end{array}$ & $\begin{array}{l}\text { X-ray: knee both-oblique, knee } \\
\text { standing AP (both) view }\end{array}$ \\
\hline $\mathrm{M} / 30$ & Passenger TA & Lt. 7 th $\sim 9$ th anterior ribs & Normal & Chest CT \\
\hline $\mathrm{M} / 44$ & Pedestrian TA & Lt. 10th rib and sternum & Normal & Chest CT \\
\hline $\mathrm{M} / 63$ & Motor cycle TA & Parietal skull & Normal & Brain CT \\
\hline $\mathrm{M} / 44$ & Passenger TA & Rt. ankle, Lt. distal tibia & $\begin{array}{l}\text { Normal on } \mathrm{P} / \mathrm{Ex} \\
\text { (X-rays were not taken) }\end{array}$ & $\begin{array}{l}\mathrm{X} \text {-ray: foot } \mathrm{AP} \text {, lat, } \\
\text { both-oblique view }\end{array}$ \\
\hline $\mathrm{M} / 27$ & Passenger TA & Multiple bilateral ribs & Normal & Chest CT \\
\hline
\end{tabular}

WBBS: whole body bone scan, P/Ex: physical examination, F: female, M: male, Lt.: left, Rt.: right, TA: traffic accident, CT: computed tomography, AP: anteroposterior, Lat: lateral.

${ }^{a)}$ Abdominal traumas. 
revealed increased uptake in the anterior and right lateral views, which indicated rib fractures. As described in Fig. 1, on the basis of the initial physical examination and X-rays, there was no abnormal findings on the areas suspected injuries in the WBBS. The WBBS detected the missed injuries most commonly on ribs $(n=7)$, followed by tibia $(n=3)$, skull $(n=2)$, ankle $(n=1)$, and sternum ( $\mathrm{n}=1)$. The newly found lesions using by WBBS were confirmed as fractures according to the presence of abnormalities on further area-specific X-rays or CT scans (Table 2). None of the missed fractures required further treatment, such as manual reduction or surgery, and all lesions were successfully treated using conservative care and symptom control.

\section{Discussion}

The current study was performed to reveal the usefulness of WBBS as a screening test for missed bone injuries of the multiple trauma patients. In patients with multiple traumas, the incidence of missed injuries has been reported to $8 \sim 65 \%[1,5,6]$. Above all, the musculoskeletal injuries are the most common type of missed injuries. Previous studies demonstrated that repeating imaging or secondary review of previous imaging studies is the most effective method to identify missed injuries [1]. Even though there was no lesion leading to long-term sequelae in this study, trauma surgeons should pay attention that clinical outcomes of missed injuries can range from no harm to prolonged disability or death [6]. From this reason, clinicians have been focused on the various diagnostic imaging tools and the more structured system of imaging review in patients with multiple traumas.

The WBBS is one of the non-invasive and simple imaging tool. Furthermore, while conventional radiographs often are initially negative, WBBS can identify bone lesions within 48 hours after trauma [7]. However, it is difficult to identify the precise etiology of the injury, as the focally increased uptake can also reflect an osteoblastic response to a local insult (e.g., a bone tumor, metastasis, or infection). In the present study, we performed further evaluations such as CT scans or lesion-specific plain $\mathrm{x}$-rays for a definitive diagnosis to overcome the limitation of WBBS.

From previous researches, rib fractures were identified in $7 \sim$
$40 \%$ of multiple trauma cases [8-11], which are also correlated to our results. A delayed diagnosis of rib fractures may result in severe pain, loss of functional lung capacity, prolonged hospitalization, and higher cost [8]. Although we did not observe a significant difference in the duration of hospitalization between patients with and without uptakes in the WBBS, it would be valuable to analyze the pain scale and total cost of hospitalization to clarify the validity of WBBS.

A Canadian report from a Level I trauma center reported that patients with missed injuries tended to be more severely injured, and to exhibit initial neurological impairment [1]. In the present study, we did not identify differences in the two groups' ISS (18.1 in the non-missed group vs. 18.4 in the missed group, $\mathrm{p}=0.897$ ). Based on these values, it appears that our patients had moderate-to-severe injuries, although all of our patients were conscious at the time of their admission and were able to undergo WBBS.

The present study has potential limitations. Owing to the nature of retrospective design, this study has risks of bias. As this study included the patients only admitted to the department of surgery, patients with head or chest injuries who were admitted to other departments could be excluded. Most importantly, we could not draw any changes in further treatment plan on the basis of findings from WBBS. From previous report by Lee et al.[8], 61.8\% of all patients had missed injuries in WBBS, and $40 \%$ of them needed additional operations or immobilization. In this study, no patients with missed injuries in the WBBS required further treatment. This uncorrelated results might be caused by small sample size and homogenous study population mainly including abdominal traumas. Thus, our findings may not generalize to other patient populations, and multicenter clinical studies are needed to validate our findings.

In conclusion, WBBS was useful for detecting missed bone injuries in patients with multiple traumas.

\section{Conflicts of Interest}

No potential conflict of interest relevant to this article was reported. 


\section{References}

1. Buduhan G, McRitchie DI. Missed injuries in patients with multiple trauma. J Trauma 2000;49:600-5.

2. Janjua KJ, Sugrue M, Deane SA. Prospective evaluation of early missed injuries and the role of tertiary trauma survey. $\mathrm{J}$ Trauma 1998;44:1000-6; discussion 1006-7.

3. Kremli MK. Missed musculoskeletal injuries in a University Hospital in Riyadh: types of missed injuries and responsible factors. Injury 1996;27:503-6.

4. Palvanen M, Kannus P, Niemi S, Parkkari J. Hospital-treated minimal-trauma rib fractures in elderly Finns: long-term trends and projections for the future. Osteoporos Int 2004;15:649-53.

5. Brooks A, Holroyd B, Riley B. Missed injury in major trauma patients. Injury 2004;35:407-10.

6. Giannakopoulos GF, Saltzherr TP, Beenen LF, Reitsma JB,
Bloemers FW, Goslings JC, et al. Missed injuries during the initial assessment in a cohort of 1124 level-1 trauma patients. Injury 2012;43:1517-21.

7. Kanstrup IL. Bone scintigraphy in sports medicine: a review. Scand J Med Sci Sports 1997;7:322-30.

8. Lee KJ, Jung K, Kim J, Kwon J. Bone scan as a screening test for missed fractures in severely injured patients. Orthop Traumatol Surg Res 2014;100:953-7.

9. Sirmali M, Türüt H, Topçu S, Gülhan E, Yazici U, Kaya S, et al. A comprehensive analysis of traumatic rib fractures: morbidity, mortality and management. Eur J Cardiothorac Surg 2003;24:133-8.

10. Harris GJ, Soper RT. Pediatric first rib fractures. J Trauma 1990;30:343-5.

11. Bulger EM, Arneson MA, Mock CN, Jurkovich GJ. Rib fractures in the elderly. J Trauma 2000;48:1040-6; discussion 1046-7. 